ARTICLE

\title{
On-surface preparation of coordinated lanthanide-transition-metal clusters
}

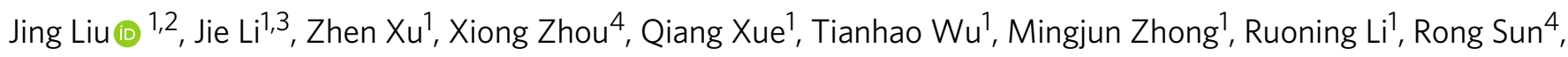
Ziyong Shen', Hao Tang ${ }^{5}$, Song Gao (1) ${ }^{2,4,6}$, Bingwu Wang ${ }^{4}$, Shimin Hou ${ }^{1,3}$ \& Yongfeng Wang (1) 1,2,6凶

The study of lanthanide (Ln)-transition-metal (TM) heterometallic clusters which play key roles in various high-tech applications is a rapid growing field of research. Despite the achievement of numerous Ln-TM cluster compounds comprising one Ln atom, the synthesis of Ln-TM clusters containing multiple Ln atoms remains challenging. Here, we present the preparation and self-assembly of a series of Au-bridged heterometallic clusters containing multiple cerium ( $\mathrm{Ce}$ ) atoms via on-surface coordination. By employing different pyridine and nitrile ligands, the ordered coordination assemblies of clusters containing 2, 3 and $4 \mathrm{Ce}$ atoms bridged by $\mathrm{Au}$ adatoms are achieved on $\mathrm{Au}(111)$ and $\mathrm{Au}(100)$, as revealed by scanning tunneling microscopy. Density functional theory calculations uncover the indispensable role of the bridging $\mathrm{Au}$ adatoms in constructing the multi-Ce-containing clusters by connecting the $\mathrm{Ce}$ atoms via unsupported $\mathrm{Ce}-\mathrm{Au}$ bonds. These findings demonstrate on-surface coordination as an efficient strategy for preparation and organization of the multi-Ln-containing heterometallic clusters.

\footnotetext{
${ }^{1}$ Key Laboratory for the Physics and Chemistry of Nanodevices and Center for Carbon-based Electronics, Department of Electronics, Peking University, Beijing, China. ${ }^{2}$ Division of Quantum State of Matter, Beijing Academy of Quantum Information Sciences, Beijing, China. ${ }^{3}$ Peking University Information Technology Institute (Tianjin Binhai), Tianjin, China. ${ }^{4}$ Beijing National Laboratory of Molecular Science, College of Chemistry and Molecular Engineering, Peking University, Beijing, China. ${ }^{5}$ CEMES, UPR CNRS 8011, Toulouse Cedex 4, France. ${ }^{6}$ Institute of Spin Science and Technology, South China University of Technology, Guangzhou, China. ${ }^{凶}$ email: yongfengwang@pku.edu.cn
} 
anthanide (Ln) series comprises lanthanum (La) and the following $14 \mathrm{f}$-block metal elements from cerium (Ce) to lutetium $(\mathrm{Lu})$. One of the research frontiers devoted to Lnengaged materials in recent years is the heterometallic compounds containing directly bonded Ln and transition-metal (TM) atoms. Such Ln-TM heterometallic compounds register various potential applications, including high-performance permanent magnets, hydrogen storage materials, luminescent materials, and catalysts, etc. ${ }^{1-3}$. Moreover, the direct (or unsupported) metal-metal bonds between $f$-block and $d$-block elements in the compounds are of great interest in terms of bonding theory. Tremendous effort has been devoted to preparation of coordination compounds involving both Ln metals and TMs by wet chemistry, resulting in a number of Ln-TM heterometallic coordination complexes featuring unsupported $d-f$ metal-metal bonds ${ }^{4-7}$. Most of these heterometallic compounds possess metal cores comprising only one $\mathrm{Ln}$ atom bonded to one or more TMcontaining metalloligand(s), whereas formation of Ln-TM clusters involving multiple $\mathrm{Ln}$ atoms as coordination centers in the compounds is scarcely reported ${ }^{8}$. The multi-Ln-containing heterometallic clusters are expected to exhibit novel properties and improved performance owning to the interactions supposed to emerge between the multiple Ln atoms in the clusters such as their magnetic coupling and synergistic effects in catalysis. Moreover, to include multiple $\mathrm{Ln}$ atoms in one Ln-TM cluster to build up larger heterometallic aggregates would also narrow the gap between molecular heterometallic complexes and intermetallic solid-state compounds. Therefore, the exploration of the preparation of Ln-TM heterometallic clusters containing multiple Ln atoms is highly desirable.

The formation of the multi-Ln-containing Ln-TM clusters stabilized by unsupported metal-metal bonds requires delicate balance among the various metal-metal and metal-ligand interactions, whose realization by wet chemistry would be rather challenging mainly due to the less controllable reaction conditions in the solvent environment. Fortunately, on-surface coordination chemistry has evolved in the past two decades to be an efficient approach to fabricating a plenty of low-dimensional metal-organic hybrid nanostructures that cannot be achieved by wet chemistry ${ }^{9-13}$. In the on-surface coordination systems, the coordination reactions are confined in the $2 \mathrm{D}$ plane due to the absorbate-substrate interactions. Moreover, the ultrahigh vacuum (UHV) condition in which the on-surface constructions of coordination structures are usually carried out ensures a solventfree reaction environment. Both facts facilitate the controllability of the coordination reactions on surfaces. On-surface coordination thus provides a potential solution to the preparation of the multi-Ln-containing Ln-TM clusters stabilized by unsupported metal-metal bonds. Recently, a series of Ln-organic hybrids have been constructed via on-surface coordination, in which either single $\mathrm{Ln}$ atoms ${ }^{14-24}$ or molecule-bridged Ln dimers ${ }^{17}$ were identified as the coordination centers. Meanwhile, the achievement of non-lanthanide metallic clusters stabilized by organic ligands on surfaces were also reported ${ }^{25-30}$. Nevertheless, the onsurface preparation of coordination complexes formed by TMbridged multi-Ln-containing heterometallic clusters has yet to be realized.

In this work, we show the preparation of a series of multi-Cecontaining heterometallic clusters in which the $\mathrm{Ce}$ atoms are bridged by $\mathrm{Au}$ atoms via the unsupported $\mathrm{Ce}-\mathrm{Au}$ bonds with an on-surface coordination strategy. By applying various molecular ligands (Fig. 1a), including the pyridines (Py) 1 [1,4-bis(4-pyridyl)-benzene], 3 [1,4-bis(4-pyridyl)-biphenyl], and 4 [1,3-bis(4pyridyl)-benzene], and the nitrile (CN) $2\left[4,4^{\prime \prime}\right.$-dicyano- $1,1^{\prime}: 3^{\prime}, 1^{\prime \prime}$ terphenyl], $\mathrm{Ce}-\mathrm{Au}$ heterometallic clusters coordinated by the organic linkers are obtained on different Au substrates [Au(111) and $\mathrm{Au}(100)$ ], as revealed by the scanning tunneling microscopy (STM) investigations. The heterometallic clusters containing 2, 3, and $4 \mathrm{Ce}$ atoms in which each pair of the nearest-neighboring $\mathrm{Ce}$ atoms are bridged by two Au adatoms assemble into ordered oneor two-dimensional (1D or 2D) structures by forming different coordination motifs with the molecular ligands (Fig. 1b), leading to mono-dispersed domains of the $\mathrm{Ce}-\mathrm{Au}$ clusters. Density functional theory (DFT) studies reveal the indispensable role of the bridging $\mathrm{Au}$ adatoms in stabilizing the multiple $\mathrm{Ce}$ atoms within one cluster by forming the unsupported $\mathrm{Ce}-\mathrm{Au}$ bonds between them. This work demonstrates on-surface coordination as an efficient strategy for preparing and organizing TM-bridged multi-Ln-containing heterometallic clusters stabilized by unsupported $d-f$ metal-metal bonds.

\section{Results}

Coordination structures involving $\mathrm{Ce}$ and pyridine ligand 1 formed on $\mathrm{Au}(\mathbf{1 1 1})$. Deposition of 1 onto the $\mathrm{Au}(111)$ substrate held at room temperature gave rise to a self-assembled structure stabilized by intermolecular hydrogen bonds (Supplementary Fig. 1a). Upon evaporation of $\mathrm{Ce}$ atoms onto the 1-precovered $\mathrm{Au}$ (111) substrate held at room temperature, the formation of a single-wall honeycomb network (Fig. 2a) was observed. The hexagonal unit cell of the new structure is highlighted by the white parallelogram in Fig. 2a with a periodicity of $2.6 \mathrm{~nm}$. This $2 \mathrm{D}$ network is distinct from that obtained by the coordination of 1 with the $\mathrm{Au}$ adatoms on $\mathrm{Au}(111)$, that is, the $1 \mathrm{D}$ molecular wires in which the molecules are connected by twofold coordination with the $\mathrm{Au}$ adatoms (Supplementary Fig. $1 \mathrm{~b})^{31}$. Therefore, it is $\mathrm{Ce}$ atoms rather than $\mathrm{Au}$ adatoms that are engaged in

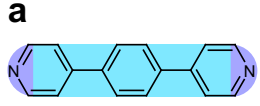

1

b

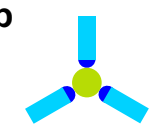

$\mathrm{CeL}_{3}$

$L=1,2,3,4$

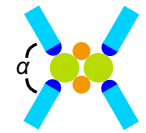

$\mathrm{Ce}_{2} \mathrm{Au}_{2} \mathrm{~L}_{4}$

$L=1,3,4$

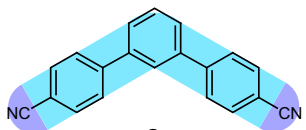

2

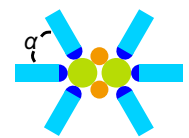

$\mathrm{Ce}_{2} \mathrm{Au}_{2} \mathrm{~L}_{6}$ $\mathrm{L}=\mathbf{2}$

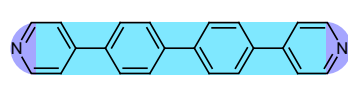

3

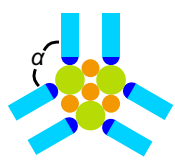

$\mathrm{Ce}_{3} \mathrm{Au}_{4} \mathrm{~L}_{6}$

$L=1,3$

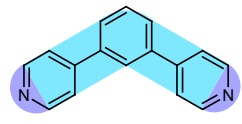

4

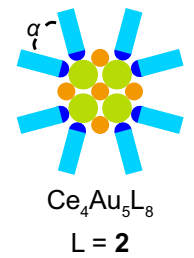

- $\mathrm{Au}$

Ligand (L)

Fig. 1 Ligands used and coordination motifs achieved in this work. a Chemical structures of the molecular ligands 1 [1,4-bis(4-pyridyl)-benzene], 2 [4,4"dicyano-1,1':3',1"-terphenyl], 3 [1,4-bis(4-pyridyl)-biphenyl], and $\mathbf{4}$ [1,3-bis(4-pyridyl)-benzene] employed in this work. b Schematic illustration of the coordination motifs achieved in this work. The angles between the ligands approaching to the same Ce atom are marked by $\alpha$. 

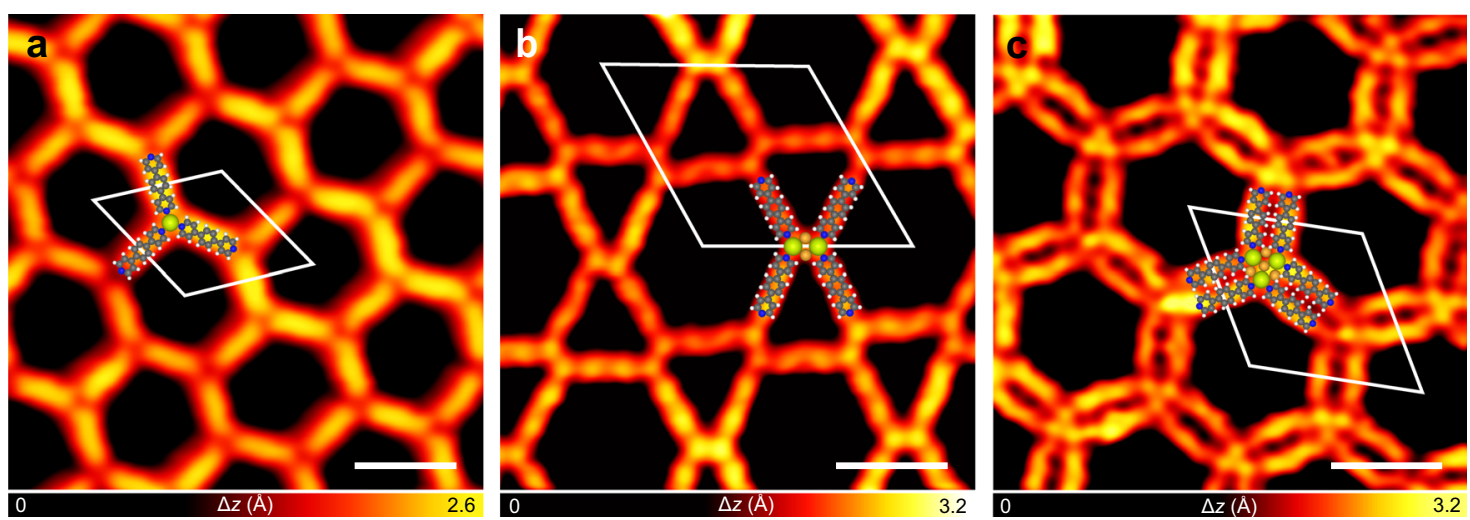

Fig. 2 Coordination structures involving Ce and 1 formed on Au(111). STM images of a the single-wall honeycomb structure (scanning conditions: bias $V=-10 \mathrm{mV}$, tunneling current $I=-30 \mathrm{pA}$, imaging temperature $T=77 \mathrm{~K})$, b the Kagome structure $(V=5 \mathrm{mV}, I=50 \mathrm{pA}, T=77 \mathrm{~K})$, and $\mathbf{c}$ the doublewall honeycomb structure $(\mathrm{V}=30 \mathrm{mV}, I=100 \mathrm{pA}, T=77 \mathrm{~K})$ formed by depositing 1 and $\mathrm{Ce}$ on Au(111). The structural motifs constructing the coordination structures are illustrated by the superimposed molecular models. Color code: dark gray for $\mathrm{C}$, white for $\mathrm{H}$, blue for $\mathrm{N}$, light green for $\mathrm{Ce}$, and orange for Au adatom. The unit cells are highlighted by the white parallelograms. Scale bars: $2 \mathrm{~nm}$.
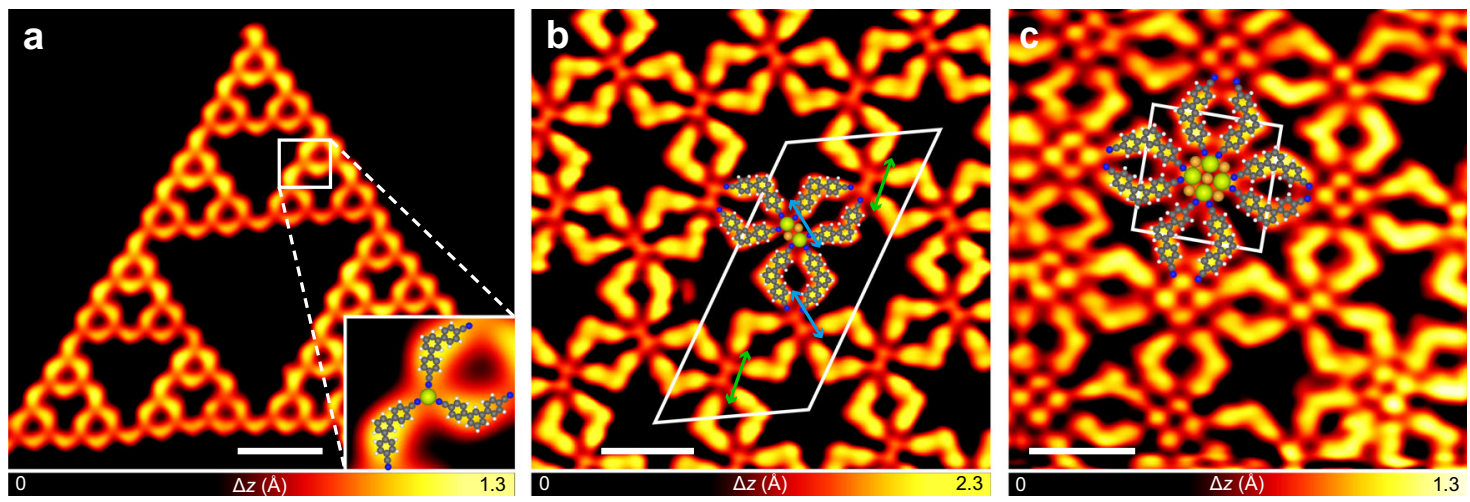

Fig. 3 Coordination structures involving Ce and 2 formed on Au(111). STM images of a a quasi-fourth-order Sierpiński triangle $(V=100 \mathrm{mV}, I=20 \mathrm{pA}$ $T=77 \mathrm{~K})$, $\mathbf{b}$ the three-lobe structure $(V=10 \mathrm{mV}, I=20 \mathrm{pA}, T=4.3 \mathrm{~K})$, and $\mathbf{c}$ the four-lobe structure $(V=10 \mathrm{mV}, I=200 \mathrm{pA}, T=4.3 \mathrm{~K})$ formed by depositing $\mathbf{2}$ and $\mathrm{Ce}$ on $\mathrm{Au}(111)$. Inset of $\mathbf{a}$ : Magnified image of the $\mathrm{Ce}(\mathrm{CN})_{3}$ building block of the Sierpiński triangles. The orientations of the Ce dimers in the three-lobe structure are marked by the green and blue arrows in $\mathbf{b}$. The unit cells are highlighted by the white parallelograms in $\mathbf{b}$ and $\mathbf{c}$. The structural motifs constructing the coordination structures are illustrated by the superimposed molecular models. Scale bars: a $5 \mathrm{~nm}$, b $2 \mathrm{~nm}$, and c $2 \mathrm{~nm}$.

the single-wall honeycomb structure. Accordingly, a model of the coordination network formed by Ce and $\mathbf{1}$ is proposed. In this model, three molecules 1 approach to a Ce atom with their pyridine ends to form coordination bonds between the pyridine$\mathrm{N}$ atoms and the Ce atom. This gives rise to the threefold mononuclear coordination node as the building block, denoted as the $\mathrm{CePy}_{3}$ motif, as illustrated by the superimposed molecular models in Fig. 2a.

Subsequent thermal treatment of the sample at about $355-375 \mathrm{~K}$ resulted in the partial desorption of the molecular ligands, which led to a decreased molecule-to-Ce ratio involved in the coordination structures as compared with that in the singlewall honeycomb network, that is, 3:2. As a consequence, two new structures with a lower molecule-to-Ce ratio (1:1) emerged, i.e., the Kagome network (Fig. 2b and Supplementary Fig. 2a) and the double-wall honeycomb network (Fig. $2 c$ and Supplementary Fig. 2b). The STM image of the Kagome structure (Fig. 2b) clearly resolves two identical bright dots (highlighted by the light green dots) at the center of each fourfold node (molecular models superimposed), which are assigned as two Ce atoms. As for the double-wall honeycomb network (Fig. 2c), one can see three bright dots in the STM image (marked by the light green dots) which are identified as a Ce trimer at the center of six molecular ligands (molecular models superimposed). Both the Kagome and the double-wall honeycomb networks feature the multi-Cecontaining clusters as the coordination centers. The clusters are organized through their coordination with the molecular ligands into the ordered $2 \mathrm{D}$ arrays. The $2 \mathrm{D}$ networks can be described by the hexagonal unit cells as marked by the white parallelograms in Fig. 2b, c with dimensions of 3.4 and $3.1 \mathrm{~nm}$, respectively.

Coordination structures involving $\mathrm{Ce}$ and nitrile ligand 2 formed on $\mathrm{Au}(\mathbf{1 1 1})$. In order to enrich the diversity of the Ce-engaged coordination structures, we employed the nitrile molecule 2 (Fig. 1a) instead of the pyridine molecule $\mathbf{1}$ as the ligand to construct coordination structures with $\mathrm{Ce}$ on $\mathrm{Au}(111)$. Without Ce adatoms, molecules 2 were found to assemble into the braid-like structures via intermolecular hydrogen bonds on $\mathrm{Au}(111)$ at room temperature (Supplementary Fig. 3). As a comparison, coordinated Sierpiński triangles ${ }^{11-13}$ (Fig. 3a and Supplementary Fig. 4a) were obtained by depositing Ce onto the 2-precovered $\mathrm{Au}(111)$ substrate held at room temperature, indicating the engagement of $\mathrm{Ce}$ atoms in the fractal structures. The building block of the Sierpiński triangles is the coordination motif formed by one Ce atom approached by three nitrile molecules, denoted as $\mathrm{Ce}(\mathrm{CN})_{3}$, as illustrated by the superimposed molecular models in Fig. 3a inset. 
By depositing more $\mathrm{Ce}$ atoms to the sample with the coordinated Sierpiński triangles on the $\mathrm{Au}(111)$ substrate followed by thermal treatment of the sample at about $350 \mathrm{~K}$, a three-lobe structure and a four-lobe structure were obtained (Fig. 3b, c and Supplementary Fig. 4b). Figure $3 \mathrm{~b}$ shows the representative STM image of the three-lobe structure, in which the two bright dots (highlighted by the light green dots) located at the center of six molecules (molecular models superimposed) are assigned as two $\mathrm{Ce}$ atoms. The orientation of the Ce dimers, as marked by the green and blue arrows in Fig. 3b, varies regularly within the domain (Supplementary Fig. 5). The unit cell of the three-lobe network is highlighted by the white parallelogram in Fig. $3 \mathrm{~b}$ with the dimensions of $a=3.4 \mathrm{~nm}, b=6.8 \mathrm{~nm}$, and an angle of about $60^{\circ}$ between them. Coexisting with the three-lobe network, the four-lobe coordination structure (Fig. 3c) features a square unit cell as marked by the white frame in Fig. $3 c$ with a periodicity of $2.3 \mathrm{~nm}$. Four bright dots are discernible in the highresolution STM image (marked by the light green dots in Fig. 3c) which are assigned as four $\mathrm{Ce}$ atoms at the center of eight molecules (molecular models superimposed in Fig. 3c).

Coordination of Ce with different molecules and on different substrates. To extend the range of conditions applicable for the on-surface preparation of the multi-Ce-containing clusters, as well as to achieve various assemblies of the clusters, the coordination of Ce with different molecules and on varied lattice planes of $\mathrm{Au}$ substrate were studied.

Firstly, we employed molecules 3 and 4 (Fig. 1a) as the ligands to construct coordination structures with $\mathrm{Ce}$ on $\mathrm{Au}(111)$. Both molecules possess pyridine coordination groups but show different backbone structures compared with the pyridine ligand 1. In addition to the mononuclear coordination structures constructed by the $\mathrm{CePy}_{3}$ motifs, i.e., the single-wall honeycomb network formed by $\mathrm{Ce}$ and 3 (Supplementary Fig. 6a) and the coordinated Sierpiński triangles formed by Ce and $\mathbf{4}$ (Supplementary Fig. 7a), the multinuclear coordiantion structures were also achieved. Figure 4 shows the three-ordered structures assembled by the coordination between the Ce dimers and ligand $\mathbf{3}$ or $\mathbf{4}$. The coordination of $\mathbf{3}$ with the two-Ce-containing clusters gives rise to a Kagome network (Fig. 4a and Supplementary Fig. $6 \mathrm{~b})$ that shows a larger periodicity $(4.5 \mathrm{~nm})$ compared with that formed by 1 (Fig. 2b), and a fishing-net structure with a hexagonal unit cell of $2.2 \mathrm{~nm}$ (Fig. $4 \mathrm{~b}$ and Supplementary Fig. 6c). The engagement of 4 leads to a chain-like structure with a 1D periodicity of $1.3 \mathrm{~nm}$ (Fig. 4c and Supplementary Fig. 7b). Besides these Ce-dimer-based structures, a low yield of the coordination motifs formed by the three-Ce-containing clusters and ligand 3 was also observed (Supplementary Fig. 6d).

Next, the coordination of Ce with either $\mathbf{1}$ or $\mathbf{2}$ was investigated on $\mathrm{Au}(100)$. As a result, the fishing-net structure (Supplementary Fig. 8a, b) and the double-wall honeycomb network (Supplementary Fig. $8 \mathrm{a}, \mathrm{c}$ ) formed by the pyridine ligand $\mathbf{1}$ and the two- or three-Cecontaining clusters, as well as the three-lobe (Supplementary Fig. 8d, e) and four-lobe (Supplementary Fig. 8d, f) structures formed by the nitrile ligand 2 and the two- or four-Ce-containing clusters were all obtained on $\mathrm{Au}(100)$.

Structures of the coordinated multi-Ce-containing clusters. The experimental observation of the coordinated clusters comprising 2, 3, and $4 \mathrm{Ce}$ atoms distinguishes the Ln-engaged onsurface coordination system studied in this work from most of the previously reported ones in which single Ln atoms were identified as the coordination centers ${ }^{14-24}$. To elucidate the structure of the multi-Ce-containing clusters, as well as to figure out the intracluster and cluster-ligand interactions, combined experimental and theoretical studies were carried out. The results reveal the heterometallic nature of the clusters, showing that the Ce atoms in the clusters are stabilized by the bridging Au adatoms, as demonstrated below.

First of all, the $\mathrm{Ce}-\mathrm{Au}$ binary surface system in the absence of molecular ligands is considered. It is documented that the preparation of $2 \mathrm{D} \mathrm{LnAu}_{2}$ intermetallic compounds has been achieved for a number of $\mathrm{Ln}$ metals, namely, $\mathrm{La}^{32}, \mathrm{Ce}^{32,33}$, $\mathrm{Gd}^{34-36}, \mathrm{~Tb}^{37,38}, \mathrm{Ho}^{37}$, and $\mathrm{Er}^{37}$, by the surface alloying of $\mathrm{Ln}$ with the $\mathrm{Au}(111)$ substrate. All these $\mathrm{LnAu}_{2}$ films share the same lattice structure in which each pair of the nearest-neighboring $\mathrm{Ln}$ atoms are bridged by two $\mathrm{Au}$ atoms ${ }^{32,34,35,37}$. Charge transfer from $\mathrm{Ln}$ to $\mathrm{Au}$ was found in these systems ${ }^{34}$, which is in accordance with the remarkable electronegativity difference between Ln and Au: Ln metals are highly electropositive while $\mathrm{Au}$ is the most electronegative metal on the Pauling scale ${ }^{39}$. The electronegativity distinction and the charge transfer are supposed to facilitate the Ln-Au intermixing but suppress the direct Ln-Ln bonding in the binary systems. Similar to Ln elements, other
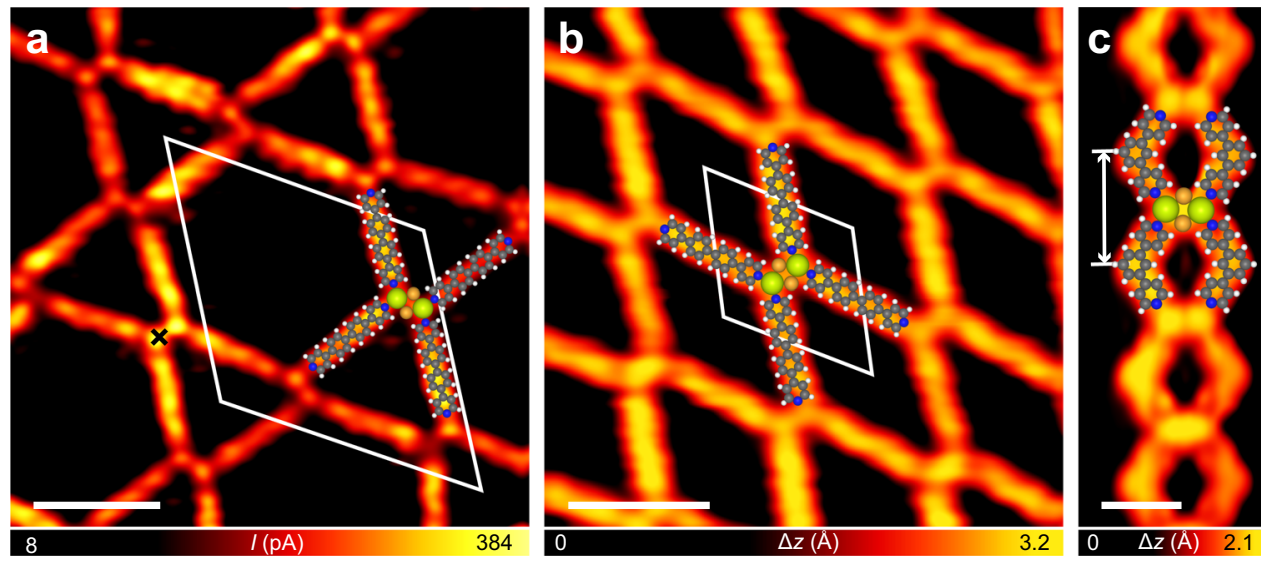

Fig. 4 Coordination structures involving $\mathbf{C e}$ and $\mathbf{3}$ or $\mathbf{4}$ formed on Au(111). STM images of a the Kagome structure (in constant-height mode, $V=5 \mathrm{mV}$, $I=350 \mathrm{pA}$ at the point marked by the cross, $T=77 \mathrm{~K})$ and $\mathbf{b}$ the fishing-net structure $(\mathrm{V}=100 \mathrm{mV}, I=20 \mathrm{pA}, T=77 \mathrm{~K})$ formed by depositing $\mathbf{3}$ and $\mathrm{Ce}$ on $\mathrm{Au}(111)$, and $\mathbf{c}$ the chain-like structure ( $\mathrm{V}=-1 \mathrm{mV}, I=-50 \mathrm{pA}, T=4.3 \mathrm{~K})$ formed by depositing 4 and Ce on Au(111). The unit cells of the Kagome and the fishing-net structures are highlighted by the white parallelograms in $\mathbf{a}$ and $\mathbf{b}$. The 1D periodicity of the chain-like structure is marked by the white arrow in $\mathbf{c}$. The structural motifs constructing the coordination structures are illustrated by the superimposed molecular models. Scale bars: a 2 nm, b 2 nm, and c $1 \mathrm{~nm}$. 
electropositive metals, e.g., the alkali metals $\mathrm{Na}^{40,41}, \mathrm{~K}^{42}$, and $\mathrm{Cs}^{43,44}$, have also been reported to form surface alloys with the $\mathrm{Au}$ substrates. Therefore, it can be summarized from the literature that the atoms of the electropositive metals, such as $\mathrm{Ce}$, usually intermix with $\mathrm{Au}$ atoms rather than directly bond with each other in the binary surface systems.

Next, we take the molecular ligands into account to demonstrate that the $\mathrm{Ce}$ atoms coordinated with the molecules are bridged by $\mathrm{Au}$ adatoms to form the multinuclear clusters observed in this work. The experimental evidence comes from both the STM and X-ray photoelectron spectroscopy (XPS) results. We conducted STM characterization of the large coordinated clusters with high nuclearities prepared by depositing $\mathrm{Ce}$ and ligand 3 on $\mathrm{Au}(111)$ followed by $530 \mathrm{~K}$ annealing, aiming at comparing the large clusters with the $\mathrm{Ce}-\mathrm{Au}$ surface intermetallic compound. As shown in Supplementary Fig. 9, clusters comprising seven or more bright dots that are assigned as Ce atoms are connected by the molecular ligands to construct the less ordered coordination structure. Both $\mathrm{Ce}$ atoms that are coordinated with the molecules (denoted as $\mathrm{Ce}_{\mathrm{L}}$, examples are marked by the blue dots in Supplementary Fig. 9) and those that are surrounded by the other Ce atoms (denoted as $\mathrm{Ce}_{\mathrm{Ce}}$, examples are marked by the red dots in Supplementary Fig. 9) can be found in the multinuclear clusters. Measurement of the $\mathrm{Ce}_{\mathrm{L}}-\mathrm{Ce}_{\mathrm{L}}$, $\mathrm{Ce}_{\mathrm{Ce}}-\mathrm{Ce}_{\mathrm{L}}$, and $\mathrm{Ce}_{\mathrm{Ce}}-\mathrm{Ce}_{\mathrm{Ce}}$ distances leads to the similar results of $5.0 \pm 0.5,5.1 \pm 0.4$, and $5.0 \pm 0.5 \AA$, respectively. All these values are comparable to the $\mathrm{Ce}-\mathrm{Ce}$ separation in the $\mathrm{CeAu}_{2}$ film grown on $\mathrm{Au}(111)$, that is, $5.4 \AA^{32}$. Moreover, the arrangement of the Ce atoms in the clusters, although distorted more or less due to the asymmetric interactions of the molecular ligands, roughly resembles the hexagonal lattice of the $\mathrm{Ce}$ atoms in the $\mathrm{CeAu}_{2}$ intermetallic compound prepared on $\mathrm{Au}(111)^{32,33}$. These results suggest that, on the one hand, the $\mathrm{Ce}_{\mathrm{Ce}}$ atoms are highly likely to be connected with each other in the same way as that in the $\mathrm{CeAu}_{2}$ surface alloy, i.e., to be bridged by $\mathrm{Au}$ adatoms, and on the other hand, the bridging $\mathrm{Au}$ adatoms are also responsible for the $\mathrm{Ce}_{\mathrm{Ce}}-\mathrm{Ce}_{\mathrm{L}}$ and $\mathrm{Ce}_{\mathrm{L}}-\mathrm{Ce}_{\mathrm{L}}$ connections given the similar $\mathrm{Ce}-\mathrm{Ce}$ separations and arrangements of the $\mathrm{Ce}_{\mathrm{Ce}}$ and $\mathrm{Ce}_{\mathrm{L}}$ atoms in the large clusters. The analyses provide clues for identifying the two-, three-, and four-Ce $\mathrm{C}_{\mathrm{L}}$-containing clusters in the ordered coordination structures as the $\mathrm{Ce}-\mathrm{Au}$ heterometallic clusters.

Furthermore, in order to figure out the chemical state of the Ce atoms in the coordinated clusters, XPS measurements were carried out for the samples with $\mathrm{Ce}$ and ligand 2 on $\mathrm{Au}(111)$. Different molecule-to-Ce ratios and annealing temperatures were employed for preparing the samples to reproduce the different coordination structures. We found shift of C $1 s$ signal toward higher binding energy by increasing the coverage of Ce (Supplementary Fig. 10a), which is attributed to the charge transfer from the ligands to the Ce atoms caused by the coordination between them. The Ce $3 d$ spectra exhibit two broad peaks (binding energies at 885 and $904 \mathrm{eV}$ ) that show negligible shifts with the varied molecule-to-Ce ratios and different annealing temperatures of the samples (Supplementary Fig. 10b). The two peaks are characteristic of Ce alloying with $\mathrm{Au}$, as demonstrated by the XPS studies of the $\mathrm{Ce}-\mathrm{Au}$ surface alloy grown on $\mathrm{Au}(111)$ in this work (bottom curve in Supplementary Fig. 10b) and the previous reports ${ }^{33,45}$. The fact that the positions of the Ce $3 d$ peaks are independent from the preparation conditions of the samples suggests the similar chemical states of the Ce atoms in the coordination structures that comprise metallic centers with different nuclearities. This is in agreement with the theoretical findings showing the similar charges carried by the Ce atoms in the different coordination centers (about $+2|e|$ per Ce atom), as described in detail below. It can be concluded from the XPS results that the coordinated clusters are composed of intermixed $\mathrm{Ce}$ and $\mathrm{Au}$ atoms.

The existence of bridging Au adatoms in the coordinated clusters is also supported by the calculation results. We start from the building block of the three-lobe structure (Fig. 3b), i.e., the coordination motif consisting of a Ce dimer and six nitrile ligands 2 , to interpret the theoretical findings. Firstly, a $\mathrm{Ce}_{2}(\mathrm{CN})_{6}$ model of the coordination motif in which the coordination center is formed by two directly approached $\mathrm{Ce}$ atoms was theoretically tested. The optimized structure of $\mathrm{Ce}_{2}(\mathrm{CN})_{6}$ in which the simplified nitrile ligands were employed is displayed in Supplementary Fig. 11a. The calculation reveals a positive charge of $+1.98|e|$ for each Ce atom due to the charge transfer between the Ce atoms and the $\mathrm{Au}$ substrate. The approaching of the two positively charged Ce atoms thus leads to a repulsive interaction between them, which is responsible for the positive (i.e., unstable) Ce-Ce binding energy of $0.30 \mathrm{eV}$, and the electron deficiency between the two Ce atoms as seen in the differential electron density map (Supplementary Fig. 11b). These results exhibit the reduced stability of the structure caused by the direct approaching of the two Ce atoms. Moreover, one can see the slight lift-up of the substrate $\mathrm{Au}$ atom between the two Ce atoms (Supplementary Fig. 11a), which is supposed to suppress the lateral movement of the coordinated Ce dimer since such a process requires frequent reconstruction of the substrate. However, in contrast to the calculation results, the tip-manipulation experiment shows the lateral displacements of the coordination motif formed by a Ce dimer and six nitrile ligands as a whole (see Supplementary Fig. 12 and Supplementary Discussion for details), and hence rejects the $\mathrm{Ce}_{2}(\mathrm{CN})_{6}$ model.

Subsequently, two models with one or two bridging Au adatom (s) located between the two $\mathrm{Ce}$ atoms, i.e., $\mathrm{Ce}_{2} \mathrm{Au}(\mathrm{CN})_{6}$ and $\mathrm{Ce}_{2} \mathrm{Au}_{2}(\mathrm{CN})_{6}$, respectively, were tested. The atomic arrangement of the $\mathrm{Ce}_{2} \mathrm{Au}_{2}$ cluster in the latter model is proposed according to the lattice structure of the $\mathrm{CeAu}_{2}$ surface intermetallic compound grown on $\mathrm{Au}(111)^{32}$. The optimized models of the two candidate structures are displayed in Supplementary Fig. 13a and Fig. 5a,
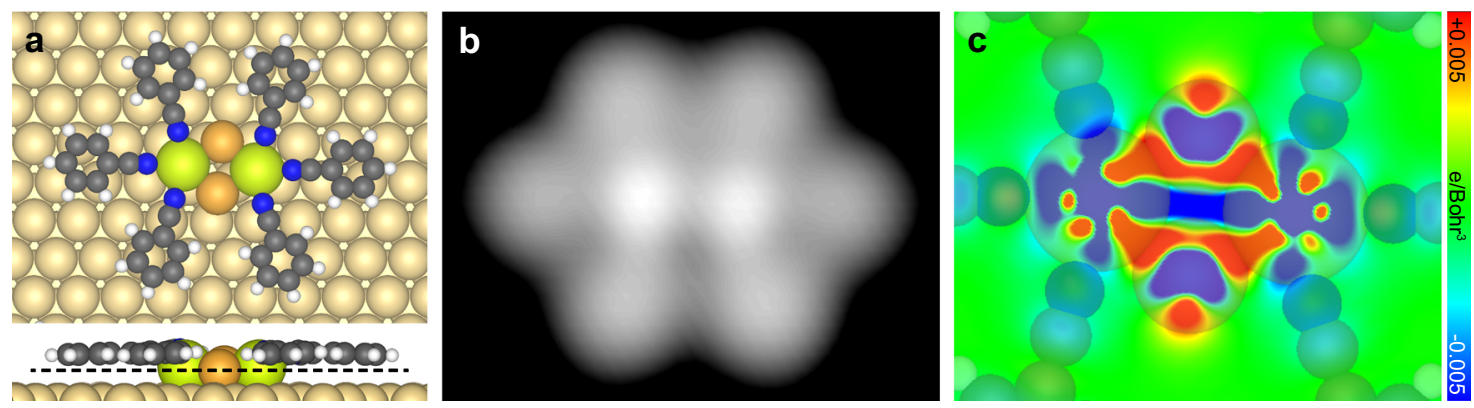

Fig. 5 Theoretical results of the $\mathbf{C e}_{\mathbf{2}} \mathbf{A u}_{\mathbf{2}}(\mathbf{C N})_{\mathbf{6}}$ structure. a DFT optimized models (upper: top view, lower: side view), b simulated STM image, and c cross-section of the differential electron density along the black dashed line in $\mathbf{a}$ of the $\mathrm{Ce}_{2} \mathrm{Au}_{2}(\mathrm{CN})_{6}$ motif on $\mathrm{Au}(111)$. Simplified molecular ligands are employed. 
respectively. The calculations reveal that the energy of the $\mathrm{Ce}_{2} \mathrm{Au}_{2}(\mathrm{CN})_{6}\left[\mathrm{Ce}_{2} \mathrm{Au}(\mathrm{CN})_{6}\right]$ structure is $1.57 \mathrm{eV}(0.75 \mathrm{eV})$ lower (i.e., more stable) than the total energy of the $\mathrm{Ce}_{2}(\mathrm{CN})_{6}$ motif plus two (one) non-interacting $\mathrm{Au}$ adatom(s). Note that the $\mathrm{Au}$ adatom absorbed on the terrace of the substrate is taken as the reference state for the energy calculation here, whereas the $\mathrm{Au}$ adatoms on the Au substrate are usually stabilized by re-attaching to the step edges in the real conditions. In the latter context, the energy differences between the proposed structures with and without the bridging $\mathrm{Au}$ adatom(s) can be estimated by subtracting the formation energy of the adatom(s) emitted from the step $\left(0.500 \mathrm{eV}\right.$ per $\mathrm{Au}$ adatom $\left.{ }^{46}\right)$ from the above-presented results. This gives rise to the energy differences of 0.57 and $0.25 \mathrm{eV}$ for $\mathrm{Ce}_{2} \mathrm{Au}_{2}(\mathrm{CN})_{6}$ and $\mathrm{Ce}_{2} \mathrm{Au}(\mathrm{CN})_{6}$, respectively, lower than $\mathrm{Ce}_{2}(\mathrm{CN})_{6}$, which still indicates an energetic preference for formation of the structures with the bridging $\mathrm{Au}$ adatom(s). Given that $\mathrm{Au}$ adatoms generated from the step and diffusing on the terrace should be well accessible on $\mathrm{Au}(111)$ under the reaction conditions ${ }^{46-50}$, we propose the most energetically preferred $\mathrm{Ce}_{2} \mathrm{Au}_{2}(\mathrm{CN})_{6}$ structure among the proposed models as the building block of the three-lobe structure, as illustrated by the superimposed molecular models in Fig. 3b. The similar phenomenon was also found by Yan et al. ${ }^{30}$ showing that the evaporated metal atoms were bridged by the intrinsic adatoms to form coordinated heterometallic clusters on surfaces. The $\mathrm{Ce}-\mathrm{Ce}$ distance in the optimized model of the $\mathrm{Ce}_{2} \mathrm{Au}_{2}(\mathrm{CN})_{6}$ motif ( $4.95 \AA)$ is consistent with the experimental value $(4.7 \pm 0.4 \AA)$ by taking the measurement error into account. Moreover, the simulated STM image of the optimized $\mathrm{Ce}_{2} \mathrm{Au}_{2}(\mathrm{CN})_{6}$ structure (Fig. 5b) was compared with those of $\mathrm{Ce}_{2}(\mathrm{CN})_{6}$ (Supplementary Fig. 11c) and $\mathrm{Ce}_{2} \mathrm{Au}(\mathrm{CN})_{6}$ (Supplementary Fig. 13b). As a result, the STM simulation of $\mathrm{Ce}_{2} \mathrm{Au}_{2}(\mathrm{CN})_{6}$ shows the best agreement with the experimental data, which supports the identification of the $\mathrm{Ce}_{2} \mathrm{Au}_{2}(\mathrm{CN})_{6}$ structure as the coordination motif to construct the three-lobe network. In both experimental images and STM simulation of $\mathrm{Ce}_{2} \mathrm{Au}_{2}(\mathrm{CN})_{6}$, the two Ce atoms are resolved as the two bright dots while the $\mathrm{Au}$ adatoms are invisible. This can be understood by the larger atomic radius of $\mathrm{Ce}$ than $\mathrm{Au}$ which leads to a larger height in $z$ direction of the former than the latter when they are adsorbed on the Au substrate, as displayed by the side view of the optimized model (Fig. 5a bottom). The similar situation that only the metal atoms with a bigger size in the heterometallic clusters are discernable by STM was also reported by Yan et al. recently ${ }^{30}$.

The higher stability of $\mathrm{Ce}_{2} \mathrm{Au}_{2}(\mathrm{CN})_{6}$ than $\mathrm{Ce}_{2}(\mathrm{CN})_{6}$ suggests that the existence of the bridging $\mathrm{Au}$ adatoms in the $\mathrm{Ce}_{2} \mathrm{Au}_{2}(\mathrm{CN})_{6}$ motif facilitates the stabilization of the coordinated cluster. In order to get insights into the stabilization effect of the bridging $\mathrm{Au}$ adatoms, Bader charge analysis of the $\mathrm{Ce}_{2} \mathrm{Au}_{2}(\mathrm{CN})_{6}$ motif was carried out. The calculations uncover positive charges on the Ce atoms $(+1.98|e|$ per $\mathrm{Ce}$ atom, Table 1$)$ and negative

\begin{tabular}{|c|c|c|}
\hline \multirow[t]{2}{*}{ Motif } & \multicolumn{2}{|c|}{ Charge (|e|) } \\
\hline & $\mathrm{Ce}$ & Au \\
\hline $\mathrm{Ce}_{2} \mathrm{Au}_{2} \mathrm{Py}_{4}$ & +1.88 & -0.59 \\
\hline $\mathrm{Ce}_{3} \mathrm{Au}_{4} \mathrm{Py}_{6}$ & +1.85 & $\begin{array}{l}-0.49 \text { (for peripheral } \mathrm{Au} \text { ) } \\
-0.56(\text { for central } \mathrm{Au})\end{array}$ \\
\hline $\mathrm{Ce}_{2} \mathrm{Au}_{2}(\mathrm{CN})_{6}$ & +1.98 & -0.47 \\
\hline $\mathrm{Ce}_{4} \mathrm{Au}_{5}(\mathrm{CN})_{8}$ & +1.87 & $\begin{array}{l}-0.51 \text { (for peripheral } \mathrm{Au} \text { ) } \\
-0.76 \text { (for central } \mathrm{Au} \text { ) }\end{array}$ \\
\hline
\end{tabular}

charges on the Au adatoms ( $-0.47|e|$ per Au adatom, Table 1). The whole coordination motif is positively charged $(+3.21|e|)$ and is stabilized by the substrate. These results demonstrate a remarkable charge transfer from the $\mathrm{Ce}$ atoms to the $\mathrm{Au}$ adatoms and the Au substrate, which is similar to the situation in the $\mathrm{Ce}-\mathrm{Au}$ binary systems as mentioned above. Therefore, the bridging Au adatoms play an indispensable role in the formation of the two-Ce-containing clusters by serving as the negatively charged "glue" to hold the two positively charged $\mathrm{Ce}$ atoms together.

The crucial role of the $\mathrm{Au}$ adatoms in stabilizing the $\mathrm{Ce}_{2} \mathrm{Au}_{2}(\mathrm{CN})_{6}$ motif is further confirmed by the formation of direct $\mathrm{Ce}-\mathrm{Au}$ bonds in the $\mathrm{Ce}_{2} \mathrm{Au}_{2}$ cluster as demonstrated by our theoretical investigations as follows. The averaged $\mathrm{Ce}-\mathrm{Au}$ distance $\left(d_{\mathrm{Ce}-\mathrm{Au}}\right)$ in the optimized $\mathrm{Ce}_{2} \mathrm{Au}_{2}(\mathrm{CN})_{6}$ model (Fig. $\left.5 \mathrm{a}\right)$ is $3.02 \AA$ (Table 2), which is smaller than the sum of their covalent radii $(3.14 \AA)^{39}$, implying the formation of unsupported $\mathrm{Ce}-\mathrm{Au}$ bonds. The calculation of the total Ce-Au binding energy $\left(E_{\mathrm{Ce}-\mathrm{Au}}^{\mathrm{tot}}\right)$ in the $\mathrm{Ce}_{2} \mathrm{Au}_{2}(\mathrm{CN})_{6}$ motif reveals an appreciable energy gain achieved by forming four direct $\mathrm{Ce}-\mathrm{Au}$ bonds in the multinuclear cluster, that is, $3.03 \mathrm{eV}$ in value (Table 2, also see "Methods" for details of the binding energy calculation). This exhibits the key effect of the $\mathrm{Ce}-\mathrm{Au}$ interactions in stabilizing the coordination structure. The formation of $\mathrm{Ce}-\mathrm{Au}$ bond is further supported by the differential electron density map of the $\mathrm{Ce}_{2} \mathrm{Au}_{2}(\mathrm{CN})_{6}$ structure (Fig. $5 \mathrm{c}$ ). The cross-section of the differential electron density depicts the electron accumulation (red) and deficiency (blue) due to the formation of the coordination motif (see "Methods" for details of the calculation of differential electron density). It is clearly seen in Fig. $5 c$ that electron density intensifies between the $\mathrm{Ce}$ and $\mathrm{Au}$ atoms, indicative of the direct $\mathrm{Ce}-\mathrm{Au}$ bond formation.

As for the cluster-ligand interaction, the optimized model of the $\mathrm{Ce}_{2} \mathrm{Au}_{2}(\mathrm{CN})_{6}$ motif (Fig. 5a) shows the coordination of three nitrile molecules to each $\mathrm{Ce}$ atom in the $\mathrm{Ce}_{2} \mathrm{Au}_{2}$ cluster. The averaged $\mathrm{Ce}-\mathrm{N}$ distance is $2.53 \AA$ (Table 2), which falls in the range of nitrile-Ce coordination bond length ${ }^{14,16,22}$. The averaged binding energy for each $\mathrm{Ce}-\mathrm{N}$ bond $\left(E_{\mathrm{Ce}-\mathrm{N}}\right)$ is $-1.30 \mathrm{eV}$ (Table 2, also see "Methods" for details of the binding energy calculation).

Given the critical role of the bridging Au adatoms in stabilizing the $\mathrm{Ce}_{2} \mathrm{Au}_{2}(\mathrm{CN})_{6}$ structure, we argue that the coordination centers of all the other multinuclear coordination structures achieved in this work are composed of the $\mathrm{Ce}-\mathrm{Au}$ heterometallic clusters in which each pair of the nearest-neighboring $\mathrm{Ce}$ atoms are bridged by two $\mathrm{Au}$ adatoms, as proposed according to the atomic arrangement of the $\mathrm{CeAu}_{2}$ surface alloy prepared on $\mathrm{Au}(111)^{32}$ (see Supplementary Fig. 14 and Supplementary Discussion for other tested models of the coordinated four-Ce-containing cluster). The optimized models are presented in Fig. $6 a-c$, showing the $\mathrm{Ce}_{2} \mathrm{Au}_{2} \mathrm{Py}_{4}$ motif as the building block of the Kagome (Figs. $2 \mathrm{~b}$ and $4 \mathrm{a}$ ), fishing-net (Fig. 4b), and chain-like (Fig. 4c) structures, while the double-wall honeycomb (Fig. 2c) and four-lobe (Fig. 3c) structures are constructed by the $\mathrm{Ce}_{3} \mathrm{Au}_{4} \mathrm{Py}_{6}$ and $\mathrm{Ce}_{4} \mathrm{Au}_{5}(\mathrm{CN})_{8}$ motifs, respectively, as illustrated by the molecular models superimposed in Figs. 2b, c, 3c, and 4. The $\mathrm{Ce}-\mathrm{Ce}$ distances in these models, i.e., $4.52 \AA$ for $\mathrm{Ce}_{2} \mathrm{Au}_{2} \mathrm{Py}_{4}, 5.56 \AA$ for $\mathrm{Ce}_{3} \mathrm{Au}_{4} \mathrm{Py}_{6}$, and $4.77 \AA$ for $\mathrm{Ce}_{4} \mathrm{Au}_{5}(\mathrm{CN})_{8}$, are consistent with the experimentally measured values, that is, $4.5 \pm 0.3,5.1 \pm 0.5$, and $4.9 \pm 0.5 \AA$, respectively. Note that the orientations of the coordination motifs with respect to the substrate as shown in Figs. 5a and $6 a-c$ have all been confirmed by the experimental observations. Bader charges of the $\mathrm{Ce}$ and $\mathrm{Au}$ atoms in these multinuclear motifs are listed in Table 1, exhibiting that the positively charged $\mathrm{Ce}$ atoms are bridged by the negatively charged $\mathrm{Au}$ adatoms. The direct $\mathrm{Ce}-\mathrm{Au}$ interactions in these structures are supported by the $d_{\mathrm{Ce}-\mathrm{Au}}$ values 


\section{Table 2 Lengths and Energies of the $\mathrm{Ce}-\mathrm{Au}$ and $\mathrm{Ce}-\mathrm{N}$ bonds in the coordination motifs.}

\begin{tabular}{llll} 
Motif & $\boldsymbol{d}_{\mathbf{C e}-\mathbf{A u}}(\boldsymbol{A})$ & $\boldsymbol{E}_{\mathbf{C e}-\mathbf{A u}}^{\text {tot }}(\mathbf{e V})$ & $\boldsymbol{d}_{\mathbf{C e}-\mathbf{N}}(\boldsymbol{\AA})$ \\
\hline $\mathrm{Ce}_{2} \mathrm{Au}_{2} \mathrm{Py}_{4}$ & 2.98 & -3.38 & 2.59 \\
$\mathrm{Ce}_{3} \mathrm{Au}_{4} \mathrm{Py}_{6}$ & 3.04 (for Ce-peripheral Au) 3.21 (for Ce-central Au) & -5.41 & -1.33 \\
$\mathrm{Ce}_{2} \mathrm{Au}_{2}(\mathrm{CN})_{6}$ & 3.02 & -3.03 & -1.31 \\
$\mathrm{Ce}_{4} \mathrm{Au}_{5}(\mathrm{CN})_{8}$ & 2.93 (for Ce-peripheral Au) 3.39 (for Ce-central Au) & -8.69 & -1.30 \\
\hline
\end{tabular}
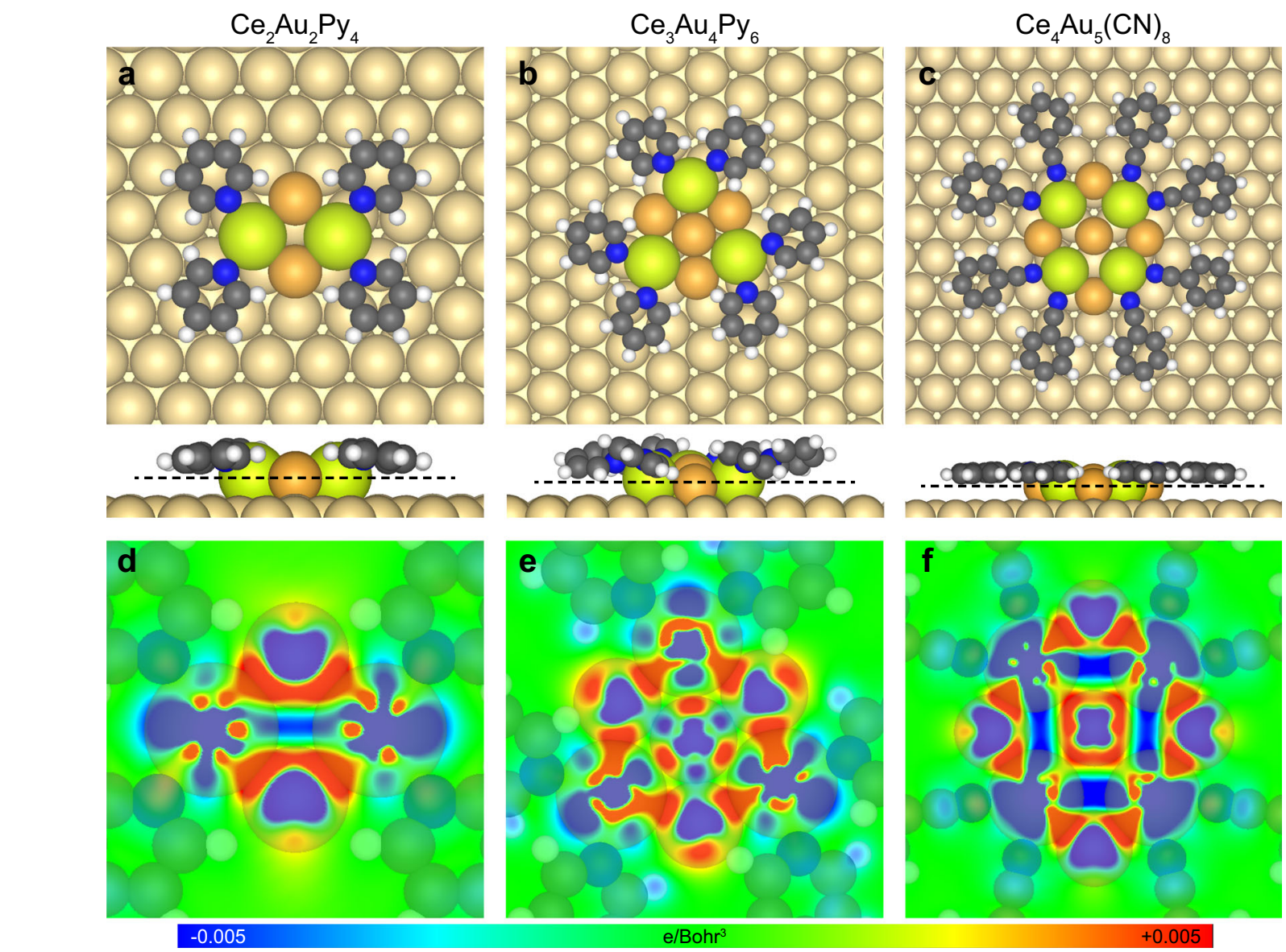

Fig. 6 Theoretical results of the multinuclear coordination structures. Optimized models of a the $\mathrm{Ce}_{2} \mathrm{Au}_{2} \mathrm{Py}_{4}, \mathbf{b}$ the $\mathrm{Ce}_{3} \mathrm{Au}_{4} \mathrm{Py}_{6}$, and $\mathbf{c}$ the $\mathrm{Ce} \mathrm{Au}_{4}(\mathrm{CN})_{8}$ motifs (upper: top view, lower: side view). Cross-sections of the differential electron densities of $\mathbf{d}$ the $\mathrm{Ce}_{2} \mathrm{Au}_{2} \mathrm{Py}_{4}, \mathbf{e}$ the $\mathrm{Ce}_{3} \mathrm{Au}_{4} \mathrm{Py}_{6}$, and $\mathbf{f}$ the $\mathrm{Ce}_{4} \mathrm{Au}_{5}(\mathrm{CN})_{8}$ motifs along the black dashed lines in $\mathbf{a}$, $\mathbf{b}$ and $\mathbf{c}$, respectively.

(Table 2) that are comparable with the sum of covalent radii of Ce and $\mathrm{Au}(3.14 \AA)^{39}$, as well as the large total $\mathrm{Ce}-\mathrm{Au}$ binding energies ( $E_{\mathrm{Ce}-\mathrm{Au}}^{\text {tot }}$ in Table 2, see "Methods" for details of the binding energy calculations). The differential electron density maps of the three multinuclear motifs (Fig. $6 \mathrm{~d}-\mathrm{f}$ ) provide another evidence for the unsupported $\mathrm{Ce}-\mathrm{Au}$ bonds by presenting the electron density accumulation between the $\mathrm{Ce}$ and $\mathrm{Au}$ atoms in these structures. As for the cluster-ligand interactions in the three multinuclear motifs, it is seen in the optimized models (Fig. 6a-c) that the coordination interactions are formed between the molecular ligands and the $\mathrm{Ce}$ atoms in the $\mathrm{Ce}-\mathrm{Au}$ clusters. The calculated Ce-ligand distances and binding energies are summarized in Table 2.

\section{Discussion}

Firstly, we compared the multinuclear coordination motifs formed by the pyridine ligands 1,3 , and 4 , i.e., $\mathrm{Ce}_{2} \mathrm{Au}_{2} \mathrm{Py}_{4}$ and $\mathrm{Ce}_{3} \mathrm{Au}_{4} \mathrm{Py}_{6}$, with those constructed by the nitrile ligand 2 , i.e.,
$\mathrm{Ce}_{2} \mathrm{Au}_{2}(\mathrm{CN})_{6}$ and $\mathrm{Ce}_{4} \mathrm{Au}_{5}(\mathrm{CN})_{8}$. It is found that the nitrileengaged multinuclear motifs show smaller angles between the ligands approaching to the same Ce atom [marked by $\alpha$ in Fig. 1b; $\alpha \sim 60-70^{\circ}$ for $\mathrm{Ce}_{2} \mathrm{Au}_{2}(\mathrm{CN})_{6}$ and $\left.\mathrm{Ce}_{4} \mathrm{Au}_{5}(\mathrm{CN})_{8}\right]$ than the ones formed by the pyridine ligands $\left(\alpha \sim 120^{\circ}\right)$. This can be explained by the smaller volume of the nitrile group than the pyridine group, which allows for the approaching of the nitrile ligands to the same metal atom with a relatively small coordination angle without introducing significant steric hinderance. The different coordination behaviors of the pyridine and nitrile ligands with the $\mathrm{Ce}-\mathrm{Au}$ clusters give rise to the various ordered coordination assemblies observed in this work, showing the feasibility of utilizing different molecular ligands to tune the organization and periodicity of the $\mathrm{Ce}-\mathrm{Au}$ cluster arrays.

Next, we discuss the possible mechanism for the formation of the multinuclear coordination structures. All the multinuclear coordination structures achieved in this work feature relatively low molecule-to-Ln ratios (no more than 3:2). Each Ce atom in these structures coordinates with two or three molecular ligands. 
As a comparison, relatively high molecule-to-Ln (or molecular coordination site-to- $\mathrm{Ln}$ in the case of chelating ligands being engaged) ratios (3:2 or higher) were frequently found for the previously reported Ln-engaged mononuclear coordination structures constructed on surfaces ${ }^{14-24}$, in which the single Ln atoms afforded multi $(\geq 3)$-fold coordination with the molecular ligands. Accordingly, we propose that the low molecule-to-Ln ratios employed for the preparation of the metal-organic hybrids in this work should play a key role in the formation of the multinuclear coordination structures.

One may expect two types of coordination products in the samples with a molecule-to-Ln ratio $\leq 3: 2$, i.e., the mononuclear structures with low coordination numbers (namely, two- or threefold coordination), and the multinuclear structures. The comparison of the stability of these two types of coordination structures can be carried out based on the calculation results shown above. For the two- and threefold mononuclear structures, the stabilizing energy per Ce atom due to the formation of the coordination bonds with the ligands can be estimated as about -2.6 and $-3.9 \mathrm{eV}$, respectively, by taking the averaged $\mathrm{Ce}-\mathrm{N}$ binding energy of the coordination structures concerned in this work for evaluation. As for the multinuclear structures constructed by the $\mathrm{Ce}_{2} \mathrm{Au}_{2} \mathrm{Py}_{4}, \mathrm{Ce}_{3} \mathrm{Au}_{4} \mathrm{Py}_{6}, \mathrm{Ce}_{2} \mathrm{Au}_{2}(\mathrm{CN})_{6}$, or $\mathrm{Ce}_{4} \mathrm{Au}_{5}(\mathrm{CN})_{8}$ motifs, the stabilizing energy per $\mathrm{Ce}$ atom contributed by the bonding with both the molecular ligands and the $\mathrm{Au}$ adatoms ranges from -4.4 to $-5.4 \mathrm{eV}$. As a conclusion, the multinuclear coordination structures are thermodynamically preferred at low molecule-to-Ln ratios. Thus, the reduction in the molecule-to-Ln ratio of the sample, which can be achieved by either deposition of additional Ce or molecular desorption caused by thermal treatment of the sample, can serve as a driving force for the emergence of the multinuclear coordination structures.

Moreover, thermal treatment of the sample is also necessary for the preparation of the multinuclear structures. In addition to tuning the molecule-to-Ln ratio by the thermal-induced molecular desorption as mentioned above, the thermal treatment also provides energies for the diffusion and rearrangement of the molecules and metal adatoms on the surface, which is indispensable for obtaining the thermodynamically preferred multinuclear products. Otherwise, coordination structures with lower stability may emerge, such as the threefold mononuclear structures (namely, the single-wall honeycomb network formed by 1 and the Sierpiński triangles formed by 2) obtained at room temperature in this work.

Last but not least, we have taken the three- and four-lobe structures constructed by the $\mathrm{Ce}_{2} \mathrm{Au}_{2}(\mathrm{CN})_{6}$ and $\mathrm{Ce}_{4} \mathrm{Au}_{5}(\mathrm{CN})_{8}$ motifs, respectively, as examples to explore the magnetic and electronic properties of the Ce-Au clusters by STS experiments. However, we failed to get any magnetic signals of the $\mathrm{Ce}-\mathrm{Au}$ clusters by high-resolution $\mathrm{d} I / \mathrm{d} V$ measurement. The similar situations have been reported for some surface-confined doubledecker lanthanide phthalocyanine molecules whose $4 f$ electron states were elusive to be detected by STS measurement ${ }^{51-54}$. The reason may lie in the inner-core nature of the $4 f$ orbitals which leads to the little contribution of the $4 f$ electron of Ce to the tunneling current. We neither found any Ce-specific $\mathrm{d} I / \mathrm{d} V$ feature in the large range $(-4$ to $3 \mathrm{~V}) \mathrm{d} I / \mathrm{d} V$ spectra. It may be explained by the strong hybridization between the Au substrate and the $\mathrm{Ce}-\mathrm{Au}$ clusters.

To summarize, a series of heterometallic clusters containing 2, 3 , and $4 \mathrm{Ce}$ atoms bridged by $\mathrm{Au}$ adatoms were prepared with an on-surface coordination strategy in UHV. STM investigations reveal the formation of ordered coordination structures based on the well-defined $\mathrm{Ce}-\mathrm{Au}$ clusters and the pyridine $(1,3$ and 4$)$ or nitrile (2) ligands on the $\mathrm{Au}(111)$ and $\mathrm{Au}(100)$ substrates, yielding orderly arranged mono-dispersed $\mathrm{Ce}-\mathrm{Au}$ cluster arrays. The $\mathrm{Au}$ adatoms serve as the atomic "glue" to bridge the $\mathrm{Ce}$ atoms via the unsupported $\mathrm{Ce}-\mathrm{Au}$ bonds, as demonstrated by the DFT calculations, which play a crucial role in stabilizing the heterometallic clusters. These results shed light on the application of on-surface coordination as an efficient strategy for the preparation and organization of TM-bridged heterometallic clusters containing multiple Ln atoms which are of great significance at both fundamental and applied levels.

\section{Methods}

Sample preparation, STM, and XPS measurements. The samples were prepared in UHV preparation chambers connected with either the STM or XPS chamber. Au (111) and $\mathrm{Au}(100)$ surfaces were cleaned by repeated cycles of $\mathrm{Ar}^{+}$sputtering and annealing. Molecules 1, 2, 3, and 4 were thermally sublimated from the tantalum boats. Ce was evaporated from an electron-beam evaporator at about $1420 \mathrm{~K}$. The thermal treatment of the samples was carried out with a temperature control within $\pm 20 \mathrm{~K}$. All STM experiments were carried out with a Unisoku UHV-STM with a base pressure lower than $3 \times 10^{-10}$ Torr in the system. STM images were acquired in constant-current mode if not otherwise specifically stated and were processed by the WSxM software ${ }^{55}$. All XPS experiments were carried out in a SPECS system with a monochromatic Al Ka X-ray source $(h v=1486.6 \mathrm{eV})$. The base pressure of the system is lower than $5 \times 10^{-10}$ Torr. The Au $4 f_{7 / 2}$ peak of a clean $\mathrm{Au}(111)$ substrate was used to calibrate the spectrometer before experiments. The Au $4 f_{5 / 2}$ peak of the $\mathrm{Au}(111)$ substrate at $87.7 \mathrm{eV}$ was employed as an internal standard to calibrate the binding energy scale for this work.

Calculation methods. All DFT calculations were performed using the projected augmented-wave (PAW) pseudopotentials ${ }^{56,57}$, as implemented in Vienna $\mathrm{Ab}$ initio Simulation Package (VASP) ${ }^{58}$. The exchange-correlation energy was calculated with the opt-B88 functional in order to take the van der Waals (vdW) dispersive correction into consideration ${ }^{59-61}$. Scalar relativistic effect which includes the mass-velocity and Darwin correction terms, as implemented in VASP $^{62}$, was taken into account. The potential of Ce was generated with 12 valence electrons including the $4 f$ electron. The cut-off energy was $400 \mathrm{eV}$ for the Kohn-Sham wave functions. A vacuum space of $10 \AA$ was applied between neighboring structures to ensure their decoupling. The initial geometries of the $\mathrm{Ce}-\mathrm{Au}$ clusters in the models for optimization were set either according to the lattice structure of the $\mathrm{CeAu}_{2}$ intermetallic compound prepared on $\mathrm{Au}(111)^{32}$, or by referring to the parameters achieved in other optimized structures studied in this work. The geometry was fully optimized when the maximum forces fell down below $0.02 \mathrm{eV}^{-1}$. A $\Gamma$ centered grid was applied for the Brillouin zone sampling.

The total Ce-Au binding energy $\left(E_{\mathrm{Ce}-\mathrm{Au}}^{\mathrm{tot}}\right)$ of the $\mathrm{Ce}_{m} \mathrm{Au}_{n} \mathrm{~L}_{k}$ (L for ligand) motif is calculated as below

$$
E_{\mathrm{Ce}-\mathrm{Au}}^{\mathrm{tot}}=E_{\mathrm{Ce}_{m} \mathrm{Au}_{n} \mathrm{~L}_{k} / \mathrm{sub}}-E_{\mathrm{Ce}_{m} \mathrm{~L}_{k} / \text { sub }}-E_{\mathrm{Au}_{n} / \text { sub }}+E_{\text {sub }}
$$

in which $E_{\mathrm{Ce}_{m} \mathrm{Au}_{n} \mathrm{~L}_{k} / \mathrm{sub}}, E_{\mathrm{Ce}_{m} \mathrm{~L}_{k} / \mathrm{sub}}, E_{\mathrm{Au}_{n} / \mathrm{sub}}$, and $E_{\text {sub }}$ refer to the energies of the $\mathrm{Ce}_{m} \mathrm{Au}_{n} \mathrm{~L}_{k}$ motif on the substrate, the $\mathrm{Ce}_{m} \mathrm{~L}_{k}$ fragment on the substrate, the $\mathrm{Au}$ adatoms on the substrate, and the $\mathrm{Au}(111)$ substrate, respectively. Here, the $\mathrm{Au}$ adatom on the terrace of the substrate is taken as the reference state for the energy calculation. The total $\mathrm{Ce}-\mathrm{Au}$ binding energy relative to the $\mathrm{Au}$ atom at the step edge can be estimated by adding the formation energy of the Au adatoms emitted from the step on $\mathrm{Au}(111)\left(0.500 \mathrm{eV}\right.$ per atom $\left.{ }^{46}\right)$ to $E_{\mathrm{Ce}-\mathrm{Au}}^{\mathrm{tot}}$. The so-achieved results still represent considerable stabilization effect of the $\mathrm{Ce}-\mathrm{Au}$ bonds.

The Ce-N binding energy $\left(E_{\mathrm{Ce}-\mathrm{N}}\right)$ of the $\mathrm{Ce}_{m} \mathrm{Au}_{n} \mathrm{~L}_{k}$ motif is calculated as below

$$
E_{\mathrm{Ce}-\mathrm{N}}=\left(E_{\mathrm{Ce}_{m} \mathrm{Au}_{n} \mathrm{~L}_{k} / \mathrm{sub}}-E_{\mathrm{Ce}_{m} \mathrm{Au}_{n} / \mathrm{sub}}-E_{\mathrm{L}_{k} / \mathrm{sub}}+E_{\text {sub }}\right) / k
$$

in which $E_{\mathrm{Ce}_{m} \mathrm{Au}_{n} / \text { sub }}$ and $E_{\mathrm{L}_{k} / \text { sub }}$ refer to the energies of the $\mathrm{Ce}_{m} \mathrm{Au}_{n}$ cluster on the substrate and the molecular ligands on the substrate, respectively.

The differential electron density $(\mathrm{d} \rho)$ is calculated as below

$$
\mathrm{d} \rho=\rho_{\text {tot }}-\rho_{\mathrm{Ce}}-\rho_{\mathrm{Au}}-\rho_{\mathrm{L}}-\rho_{\text {sub }}
$$

where $\rho_{\text {tot }}, \rho_{\mathrm{Ce}}, \rho_{\mathrm{Au}}, \rho_{\mathrm{L}}$, and $\rho_{\text {sub }}$ correspond to the electron densities of the total system, the Ce atom, the Au adatom, the molecular ligand, and the substrate, respectively.

\section{Data availability}

The data that support the findings of this study are available within the paper and its supplementary information file. Raw data are available from the corresponding author upon reasonable request.

Received: 21 August 2020; Accepted: 19 February 2021; Published online: 12 March 2021 


\section{References}

1. Fidler, J., Suess, D. \& Schrefl, T. Handbook of Magnetism and Advanced Magnetic Materials Vol. 4 (Wiley, 2007).

2. David, E. An overview of advanced materials for hydrogen storage. J. Mater. Process Technol. 162-163, 169-177 (2005).

3. Huang, Y.-G., Jiang, F.-L. \& Hong, M.-C. Magnetic lanthanide-transitionmetal organic-inorganic hybrid materials: from discrete clusters to extended frameworks. Coord. Chem. Rev. 253, 2814-2834 (2009).

4. Liddle, S. T. \& Mills, D. P. Metal-metal bonds in f-element chemistry. Dalton Trans. https://doi.org/10.1039/b904318g (2009).

5. Butovskii, M. V. et al. Molecules containing rare-earth atoms solely bonded by transition metals. Nat. Chem. 2, 741-744 (2010).

6. Oelkers, B., Butovskii, M. V. \& Kempe, R. f-Element-metal bonding and the use of the bond polarity to build molecular intermetalloids. Chem. Eur. J. 18 13566-13579 (2012).

7. Butovskii, M. V. et al. Lanthanoid-transition-metal bonding in bismetallocenes. Chem. Eur. J. 20, 2804-2811 (2014).

8. Butovskii, M. V., Tok, O. L., Bezugly, V., Wagner, F. R. \& Kempe, R. Molecular lanthanoid-transition-metal cluster through C-H bond activation by polar metal-metal bonds. Angew. Chem. Int. Ed. 50, 7695-7698 (2011).

9. Dong, L., Gao, Z. A. \& Lin, N. Self-assembly of metal-organic coordination structures on surfaces. Prog. Surf. Sci. 91, 101-135 (2016)

10. Lin, T., Kuang, G., Wang, W. \& Lin, N. Two-dimensional lattice of out-ofplane dinuclear iron centers exhibiting kondo resonance. ACS Nano 8, 8310-8316 (2014)

11. Zhang, X. et al. Controlling molecular growth between fractals and crystals on surfaces. ACS Nano 9, 11909-11915 (2015).

12. Li, C. et al. Construction of Sierpiński triangles up to the fifth order. J. Am Chem. Soc. 139, 13749-13753 (2017).

13. Zhang, X. et al. One-dimensional molecular chains formed by Sierpiński triangles on $\mathrm{Au}(111)$. RSC Adv. 8, 1852-1856 (2018).

14. Écijaa, D. et al. Five-vertex archimedean surface tessellation by lanthanidedirected molecular self-assembly. Proc. Natl Acad. Sci. USA 110, 6678-6681 (2013).

15. Bischoff, F. et al. Metalation of porphyrins by lanthanide atoms at interfaces: direct observation and stimulation of cerium coordination to $2 \mathrm{H}-\mathrm{TPP} / \mathrm{Ag}$ (111). J. Phys. Chem. C 122, 5083-5092 (2018).

16. Ecija, D., Urgel, J. I., Seitsonen, A. P., Auwarter, W. \& Barth, J. V. Lanthanidedirected assembly of interfacial coordination architectures-from complex networks to functional nanosystems. Acc. Chem. Res. 51, 365-375 (2018)

17. Cirera, B. et al. Dysprosium-carboxylate nanomeshes with tunable cavity size and assembly motif through ionic interactions. Chem. Commun. 52, 11227-11230 (2016)

18. Cirera, B. et al. Long-range orientational self-assembly, spatially controlled deprotonation, and off-centered metalation of an expanded porphyrin. J. Am. Chem. Soc. 139, 14129-14136 (2017).

19. Lyu, G. et al. Tunable lanthanide-directed metallosupramolecular networks by exploiting coordinative flexibility through ligand stoichiometry. Chem. Commun. 52, 1618-1621 (2016).

20. Urgel, J. I. et al. Quasicrystallinity expressed in two-dimensional coordination networks. Nat. Chem. 8, 657-662 (2016).

21. Urgel, J. I., Ecija, D., Auwarter, W. \& Barth, J. V. Controlled manipulation of gadolinium-coordinated supramolecules by low-temperature scanning tunneling microscopy. Nano Lett. 14, 1369-1373 (2014).

22. Urgel, J. I. et al. Five-vertex lanthanide coordination on surfaces: a route to sophisticated nanoarchitectures and tessellations. J. Phys. Chem. C 118, 12908-12915 (2014)

23. Urgel, J. I. et al. Surface-supported robust 2D lanthanide-carboxylate coordination networks. Small 11, 6358-6364 (2015).

24. Fan, Q. et al. Template-controlled on-surface synthesis of a lanthanide supernaphthalocyanine and its open-chain polycyanine counterpart. Nat. Commun. 10, 5029 (2019).

25. Classen, T. et al. Templated growth of metal-organic coordination chains at surfaces. Angew. Chem. 44, 6142-6145 (2005).

26. Wang, W. et al. Inspecting metal-coordination-induced perturbation of molecular ligand orbitals at a submolecular resolution. J. Phys. Chem. Lett. 1, 2295-2298 (2010).

27. Wang, W., Wang, S., Hong, Y., Tang, B. Z. \& Lin, N. Selective supramolecular assembly of multifunctional ligands on a $\mathrm{Cu}(111)$ surface: metallacycles, propeller trimers and linear chains. Chem. Commun. 47, 10073-10075 (2011).

28. Knecht, P. et al. The self-assembly and metal adatom coordination of a linear bis-tetrazole ligand on $\mathrm{Ag}(111)$. Chem. Commun. 54, 10072-10075 (2018).

29. Krull, C. et al. Iron-based trinuclear metal-organic nanostructures on a surface with local charge accumulation. Nat. Commun. 9, 3211 (2018).

30. Yan, L. et al. Stabilizing and organizing $\mathrm{Bi}_{3} \mathrm{Cu}_{4}$ and $\mathrm{Bi}_{7} \mathrm{Cu}_{12}$ nanoclusters in two-dimensional metal-organic networks. Angew. Chem. Int. Ed. 57, 4617-4621 (2018).
31. Zhang, $X$. et al. Influence of relativistic effects on assembled structures of $\mathrm{V}$-shaped bispyridine molecules on $\mathrm{M}(111)$ surfaces where $\mathrm{M}=\mathrm{Cu}, \mathrm{Ag}, \mathrm{Au}$. ACS Nano 11, 8511-8518 (2017).

32. Ormaza, M. et al. $\mathrm{LaAu}_{2}$ and $\mathrm{CeAu}_{2}$ surface intermetallic compounds grown by high-temperature deposition on Au(111). Phys. Rev. B 88, 125405 (2013).

33. Ma, S., Zhao, X., Rodriguez, J. A., Hrbek, J. \& STM, X. P. S. study of growth of Ce on $\mathrm{Au}(111)$. J. Phys. Chem. C 111, 3685-3691 (2007).

34. Corso, M. et al. Rare-earth surface alloying: a new phase for $\mathrm{GdAu}_{2}$. Phys. Rev. Lett. 105, 016101 (2010).

35. Corso, M., Fernández, L., Schiller, F. \& Ortega, J. E. Au(111)-based nanotemplates by Gd alloying. ACS Nano 4, 1603-1611 (2010).

36. Fernández, L. et al. Self-organized growth of high density magnetic Co nanodot arrays on a Moiré template. Appl. Phys. Lett. 96, 013107 (2010).

37. Que, Y. et al. Two-dimensional rare earth-gold intermetallic compounds on $\mathrm{Au}(111)$ by surface alloying. J. Phys. Chem. Lett. 11, 4107-4112 (2020).

38. Que, Y. et al. On-surface synthesis of graphene nanoribbons on twodimensional rare earth-gold intermetallic compounds. J. Phys. Chem. Lett. 11, 5044-5050 (2020)

39. Haynes, W. M. (ed.). CRC Handbook of Chemistry and Physics 95th edn (CRC Press, 2014)

40. Barth, J. V., Brune, H., Schuster, R. \& Ertl, G. Intermixing and twodimensional alloy formation in the $\mathrm{Na} / \mathrm{Au}(111)$ system. Surf. Sci. Lett. 292, L769-L774 (1993).

41. Barth, J. V., Behm, R. J. \& Ertl, G. Adsorption, surface restructuring and alloy formation in the $\mathrm{Na} / \mathrm{Au}(111)$ system. Surf. Sci. 341, 62-91 (1995).

42. Barth, J. V., Schuster, R., Behm, R. J. \& Ertl, G. The system K/Au(111) adsorption and surface restructuring. Surf. Sci. 348, 280-286 (1996).

43. Wertheim, G. K., Rowe, J. E., Chiang, C.-M., Malic, R. A. \& Buchanan, D. N E. Surface properties of the semiconductor CsAu. Surf. Sci. 330, 27-33 (1995).

44. Knat'ko, M. V., Lapushkin, M. N. \& Paleev, V. I. Initial stages in the formation of a CsAu surface alloy. Tech. Phys. Lett. 24, 390-392 (1998).

45. Zhao, X., Ma, S., Hrbek, J. \& Rodriguez, J. A. Reaction of water with Ce-Au (111) and $\mathrm{CeO}_{\mathrm{x}} / \mathrm{Au}(111)$ surfaces: photoemission and STM studies. Surf. Sci. 601, 2445-2452 (2007).

46. Stoltze, P. Simulation of surface defects. J. Phys. Condens. Matter 6, 9495-9517 (1994).

47. Sun, Q., Cai, L., Ma, H., Yuan, C. \& Xu, W. Dehalogenative homocoupling of terminal alkynyl bromides on $\mathrm{Au}(111)$ : incorporation of acetylenic scaffolding into surface nanostructures. ACS Nano 10, 7023-7030 (2016)

48. Rastgoo-Lahrood, A. et al. From Au-thiolate chains to thioether Sierpinski triangles: the versatile surface chemistry of 1,3,5-tris(4-mercaptophenyl) benzene on Au(111). ACS Nano 10, 10901-10911 (2016).

49. Zhang, H. \& Chi, L. Gold-organic hybrids: on-surface synthesis and perspectives. Adv. Mater. 28, 10492-10498 (2016).

50. Liu, M. et al. Graphene-like nanoribbons periodically embedded with fourand eight-membered rings. Nat. Commun. 8, 14924 (2017).

51. Komeda, T. et al. Observation and electric current control of a local spin in a single-molecule magnet. Nat. Commun. 2, 217 (2011).

52. Schwöbel, J. et al. Real-space observation of spin-split molecular orbitals of adsorbed single-molecule magnets. Nat. Commun. 3, 953 (2012).

53. Yajie, Z. et al. Low-temperature scanning tunneling microscopy study on the electronic properties of a double-decker $\mathrm{DyPc}_{2}$ molecule at the surface. Phys. Chem. Chem. Phys. 17, 27019-27026 (2015).

54. Yajie, Z. et al. Detection and manipulation of charge states for double-decker $\mathrm{DyPc}_{2}$ molecules on ultrathin CuO films. ACS Nano 12, 2991-2997 (2018).

55. Horcas, I. et al. WSXM: a software for scanning probe microscopy and a too for nanotechnology. Rev. Sci. Instrum. 78, 013705 (2007).

56. Blöchl, P. E. Projector augmented-wave method. Phys. Rev. B 50, 17953-17979 (1994).

57. Kresse, G. \& Joubert, D. From ultrasoft pseudopotentials to the projector augmented-wave method. Phys. Rev. B 59, 1758-1775 (1999).

58. Kresse, G. \& Furthmuller, J. Efficient iterative schemes for ab initio totalenergy calculations using a plane-wave basis set. Phys. Rev. B 54, 11169 (1996)

59. Klimes, J., Bowler, D. R. \& Michaelides, A. Chemical accuracy for the van der Waals density functional. J. Phys. Condens. Matter 22, 022201 (2010).

60. Lee, K., Murray, É. D., Kong, L., Lundqvist, B. I. \& Langreth, D. C. Higheraccuracy van der Waals density functional. Phys. Rev. B 82, 081101 (2010).

61. Klimeš, J., Bowler, D. R. \& Michaelides, A. Van der Waals density functionals applied to solids. Phys. Rev. B 83, 195131 (2011).

62. Hafer, J. Ab-initio simulations of materials using VASP: density-functional theory and beyond. J. Comput. Chem. 29, 2044-2078 (2008).

\section{Acknowledgements}

This work was supported by the Ministry of Science and Technology (2018YFA0306003, 2017YFA0205003) and National Natural Science Foundation of China (22001017, 21972002, and 21991132). DFT calculations were carried out on TianHe-1A at National Supercomputer Center in Tianjin and supported by high-performance computing platform of Peking University. 


\section{Author contributions}

Y.W. designed the experiment; J. Liu, Z.X., Q.X., and R.L. conducted the STM experiments; J. Li., R.S., H.T., and B.W. carried out DFT calculations; X.Z,. T.W., and M.Z. conducted the XPS experiments; J. Liu, Q.X., S.G., Z.S., B.W., S.H., and Y. W. analyzed the data; S.G., Z.S., B.W., and S.H. participated in manuscript writing; J. Liu, Q.X., and Y.W. wrote the manuscript. All authors discussed the results and commented on the manuscript.

\section{Competing interests}

The authors declare no competing interests.

\section{Additional information}

Supplementary information The online version contains supplementary material available at https://doi.org/10.1038/s41467-021-21911-z.

Correspondence and requests for materials should be addressed to Y.W.

Peer review information Nature Communications thanks J. Michael Gottfried and the other, anonymous, reviewer(s) for their contribution to the peer review of this work. Peer reviewer reports are available.
Reprints and permission information is available at http://www.nature.com/reprints

Publisher's note Springer Nature remains neutral with regard to jurisdictional claims in published maps and institutional affiliations.

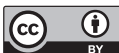

Open Access This article is licensed under a Creative Commons Attribution 4.0 International License, which permits use, sharing, adaptation, distribution and reproduction in any medium or format, as long as you give appropriate credit to the original author(s) and the source, provide a link to the Creative Commons license, and indicate if changes were made. The images or other third party material in this article are included in the article's Creative Commons license, unless indicated otherwise in a credit line to the material. If material is not included in the article's Creative Commons license and your intended use is not permitted by statutory regulation or exceeds the permitted use, you will need to obtain permission directly from the copyright holder. To view a copy of this license, visit http://creativecommons.org/ licenses/by/4.0/.

(C) The Author(s) 2021 